\title{
Article
}

\section{Risk factors associated with the development of metastases in patients with gastroenteropancreatic neuroendocrine tumors}

\author{
Shuzo Kohno ${ }^{{ }^{*}}$, Masahiro Ikegami ${ }^{2}$, Toru Ikegami ${ }^{3}$, Hiroaki Aoki ${ }^{1}$, Masaichi Ogawa ${ }^{1}$, Fumiaki Yano ${ }^{3}$ and Ken \\ Eto $^{3}$
}

1 Department of Surgery, The Jikei University Katsushika Medical Center, 125-8061 Tokyo, Japan

2 Department of Pathology, The Jikei University Katsushika Medical Center, 125-8061 Tokyo, Japan

3 Department of Surgery, The Jikei University School of Medicine, 105-8461, Tokyo, Japan

* Correspondence: Shuzo Kohno, MD, PhD, Department of Surgery, The Jikei University Katsushika Medical Center, 6-41-2 Aoto, Katsushika-ku, Tokyo 125-8061, Japan; s-kohno@jikei.ac.jp; Tel.: +81-3-3603-2111 Fax: $+81-03-3838-9945$

Simple Summary: Neuroendocrine tumors develop from systemic endocrine and nerve cells, and their prevalence has increased in recent years. Since the characteristics of these tumors are diverse, they have been scientifically classified according to the organ in which they occur. In the 2019 World Health Organization classification, gastroenteropancreatic neuroendocrine tumors are grouped together, a change that is expected to affect how research proceeds. In this study, we examined data regarding this new classification to investigate the metastasis of gastroenteropancreatic neuroendocrine tumors. Neuroendocrine tumor grade and vascular factors were related to tumor metastasis, although the method of identification and criteria for lymphatic invasion were identified as problematic. Accordingly, we recommend that the characteristics of the entire tumor be investigated. In future studies, we aim to identify other problematic aspects of studying the characteristics of neuroendocrine tumors.

\begin{abstract}
Neuroendocrine tumors develop from systemic endocrine and nerve cells, and their occurrence has increased recently. Since these tumors are heterogeneous, pathological classification has been based on the affected organ. In 2019, the World Health Organization introduced a change that is expected to influence neuroendocrine tumor research, as gastroenteropancreatic neuroendocrine tumors are now included within a unified classification. In this retrospective study, we aimed to investigate the characteristics (e.g., lymph node metastases, all other metastases) of gastroenteropancreatic neuroendocrine tumors using this new classification in 50 cases. Tumor size, depth, MIB-1 index, lymphatic invasion, venous invasion, and neuroendocrine tumor grade were significantly correlated with lymph node metastasis and all other metastases. Venous invasion was more strongly correlated with lymph node metastasis and all other types of metastasis than with lymphatic invasion. Identification rates for lymphatic invasion were considered lower because of structural problems such as lymphatic vessels being much thinner than veins. However, venous invasion was considered effective in compensating for the low rate of identification in cases of lymphatic invasion. In future research, a unified classification and standardized framework for assessment will be important when analyzing the characteristics of neuroendocrine tumors, and large-scale studies are required.
\end{abstract}

Keywords: neuroendocrine tumor; metastasis; lymphatic invasion; venous invasion

\section{Introduction}

Neuroendocrine tumors (NETs) are heterogeneous malignancies with various pathological and clinical features [1-3] that arise from systemic endocrine and nerve cells, and their prevalence has been increasing of late [4]. Previously, NET classification was based on the organ in which the tumor developed. However, according to the 2019 World 
Health Organization classification, NETs occurring in all gastroenteropancreatic (GEP) organs have been grouped together and reclassified [5]. Basic and clinical studies have promoted advancements in the diagnosis and treatment of NETs [6,7], and the reclassification of NETs is expected to further advance this research [6].

Treatment guidelines have been created for NETs in each organ, mainly in Europe and the United States [8-11]. Tumor resection is an effective and important treatment option, with radical treatment involving complete removal of the tumor [8]. Localized NETs are an indication for endoscopic and surgical resection. Indications for endoscopic treatment are determined by the grade, depth, and size of the tumor. For localized tumors that are not indicated for endoscopic resection, the indication for surgical resection is determined based on whether the metastatic lesion can be completely resected $[8,12,13]$. Thus, the diagnosis and prediction of metastasis, especially lymph node metastasis, is important when selecting the treatment option to be used for a particular NET. Lymph node metastases may be surgically removed, which can improve prognosis, although other metastases are difficult to remove surgically and are often not indicated for surgery, highlighting the need for preoperative evaluation. Therefore, in the present study, we aimed to examine the factors related to lymph node metastases and all other types of metastases in the new GEP-NET classification, as well as the problems that can arise when identifying these factors.

\section{Materials and Methods}

\subsection{Patients}

The medical histories of 48 patients with 50 consecutive cases of GEP-NET treated via endoscopic or surgical resection at our institution between January 2010 and March 2021 were retrospectively collected and compared. Patients that refused treatment and cases in which tumor size was unknown were excluded. Data related to age, sex, body mass index, and pathological tumor findings (site, size, depth of invasion, lymphatic invasion, venous invasion, and MIB-1 index) were obtained from electronic medical records for all patients.

\subsection{Pathological Classification and Staging}

The diagnosis and treatment of patients were evaluated based on contemporary standards. NET classification was based on the 2019 World Health Organization classification [14]. All GEP-NETs were classified into well-differentiated NETs, poorly differentiated neuroendocrine carcinomas, and mixed endocrine/non-endocrine neoplasms. Well-differentiated NETs were classified into grades 1, 2, and 3 (G1, G2, and G3) based on the mitotic rate and Ki-67 index (G1, mitotic rate of <2 per 10 high-power fields and/or Ki67 index of $<3 \%$; G2, mitotic rate of 2 to 20 per 10 high-power fields and/or Ki67 index of 3 to 20\%; and G3, mitotic rate of $>20$ per 10 high-power fields and/or Ki67 index of $>20 \%$ ). Neuroendocrine carcinomas were classified as small- or large-cell types. Mixed endocrine/non-endocrine neoplasms consisted of a neuroendocrine component or a non-neuroendocrine component, such as an adenocarcinoma. For endoscopically resected specimens, a cut surface was created at the center of the lesion. In addition to hematoxylin and eosin staining, synaptophysin, chromogranin, CD56, and Ki67 staining were performed on all resected lesions. Lymphatic invasion was diagnosed via D2-40 staining [15], and venous invasion was diagnosed via Elastica van Gieson staining [16].

\subsection{Statistical Analysis}

Univariate and multivariate analyses for age, sex, body mass index, tumor size, site of origin, depth, MIB-1 index, lymphatic invasion, venous invasion, and NET grade for lymph node metastases and all metastases were performed using logistic regression analysis. The effects of lymphatic invasion and venous invasion on lymph node metastases and all metastases were analyzed using Fisher's exact test. Statistical 
significance was set at $\mathrm{p}<0.05$. Statistical analyses were performed using SPSS Statistics version 22.0 (IBM Japan, Ltd., Tokyo, Japan).

\section{Results}

\subsection{Background Data}

The background data of all patients with GEP-NET who underwent endoscopic or surgical resection at our institution during the study period are shown in Table 1. Fifty resections were performed in 48 patients with NETs.

There were three deaths. The first patient died due to brain metastasis of esophageal neuroendocrine carcinoma 3 years and 10 months after a subtotal esophagectomy; the second patient died of sepsis due to a perianal abscess with rectal, duodenal, and intraperitoneal recurrence 7 years and 5 months after endoscopic resection for rectal NET G2; and the third patient died 2 months after sigmoid resection for a perforated intraperitoneal abscess of a sigmoid colon NET with liver and multiple lymph node metastases.

Table 1. Background characteristics of patients ( $n=50$ tumors)

\begin{tabular}{|c|c|c|}
\hline Characteristic & & Value \\
\hline Age (years) & Mean \pm SD & $60.3 \pm 14.1$ \\
\hline \multirow[t]{2}{*}{ Sex, n (\%) } & Male (\%) & $35(70)$ \\
\hline & Female (\%) & $15(30)$ \\
\hline Body mass index & Mean \pm SD & $23.67 \pm 4.11$ \\
\hline Size (mm) & Mean \pm SD & $9.06 \pm 9.22$ \\
\hline \multirow[t]{2}{*}{ Excision method } & Endoscopic resection & 36 \\
\hline & Surgical resection & 14 \\
\hline \multirow[t]{6}{*}{ Location } & Esophagus & 2 \\
\hline & Stomach & 6 \\
\hline & Duodenum & 7 \\
\hline & Small intestine & 2 \\
\hline & Pancreas & 3 \\
\hline & Colon & 1 \\
\hline
\end{tabular}


Rectum 31

\begin{tabular}{|c|c|c|}
\hline \multirow[t]{2}{*}{ Depth } & \multirow{2}{*}{$\begin{array}{l}\mathrm{T} 1 \mathrm{a} \\
\mathrm{T} 1 \mathrm{~b}(+\mathrm{c})\end{array}$} & \multirow{2}{*}{$\begin{array}{c}7 \\
34\end{array}$} \\
\hline & & \\
\hline & $\mathrm{T} 2$ & 6 \\
\hline & $\mathrm{T} 3$ & 2 \\
\hline & $\mathrm{T} 4$ & 1 \\
\hline \multirow[t]{2}{*}{ MIB-1 index } & $<3 \%$ & 36 \\
\hline & $>3 \%$ & 14 \\
\hline \multirow[t]{4}{*}{ Grade } & Grade 1 & 39 \\
\hline & Grade 2 & 7 \\
\hline & Grade 3 & 0 \\
\hline & NEC & 4 \\
\hline Characteristic & Yes & No \\
\hline Lymphatic invasion (n) & 10 & 40 \\
\hline Venous invasion (n) & 13 & 37 \\
\hline
\end{tabular}

SD, standard deviation; NEC, neuroendocrine carcinoma.T1a, intramucosal; T1b, submucosal; T2, muscularis propria; T3, subserosal; T4, extraserosal infiltration. In the pancreas, T1: localized to the pancreas (maximum diameter $\leq 2 \mathrm{~cm}$ ), T2 (localized to the pancreas, $2 \mathrm{~cm}<$ maximum diameter $\leq 4 \mathrm{~cm}$ ), T3: (localized to the pancreas, $4 \mathrm{~cm}<$ maximum diameter/duodenum/bile duct infiltration).

The average observation period was 925.3 days. There were 35 (70\%) men and 15 (30\%) women, and the patient age ranged from 33-88 years (average, 60.4 years). The mean body mass index was $23.67 \pm 4.11$. The resection method was endoscopic resection in 36 cases and surgical resection in 14 cases. Surgical resection included cases performed after endoscopic resection and those performed after examination without endoscopic resection. The esophagus was resected in 2 cases, the stomach in 6 , duodenum in 7 , small intestine in 2, pancreas in 3, colon in 2, and rectum in 31. The invasion depth was intramucosal in 7 cases, submucosal (in the pancreas, the tumor remained in the organ and did not infiltrate adjacent organs) in 34 cases, up to the muscularis propria in 6 cases, up to the serosa in 2 cases, and extraserosal in 1 case. The metastasis was observed in 8 cases (16.7\%). The metastatic sites occurred in the lymph nodes, liver, lung, and brain in $6,3,1$, and 1 cases, respectively; there was 1 case of dissemination.

\subsection{Venous and Lymphatic Invasion}

Lymphatic invasion of resected specimens was reported in eight cases before this study, but two small metastatic lesions (Figure 1) were diagnosed again by a different 
pathologist, resulting in a total of 10 cases $(20 \%)$. The lesions identified via repeat microscopy with D2-40 staining exhibited very small amounts of NET cells in vertically or diagonally cut lymphatic vessels. Intravenous invasion was observed in 13 cases (26\%). Venous invasion was identified in all six cases of lymph node metastasis, while lymphatic invasion was identified in four cases.

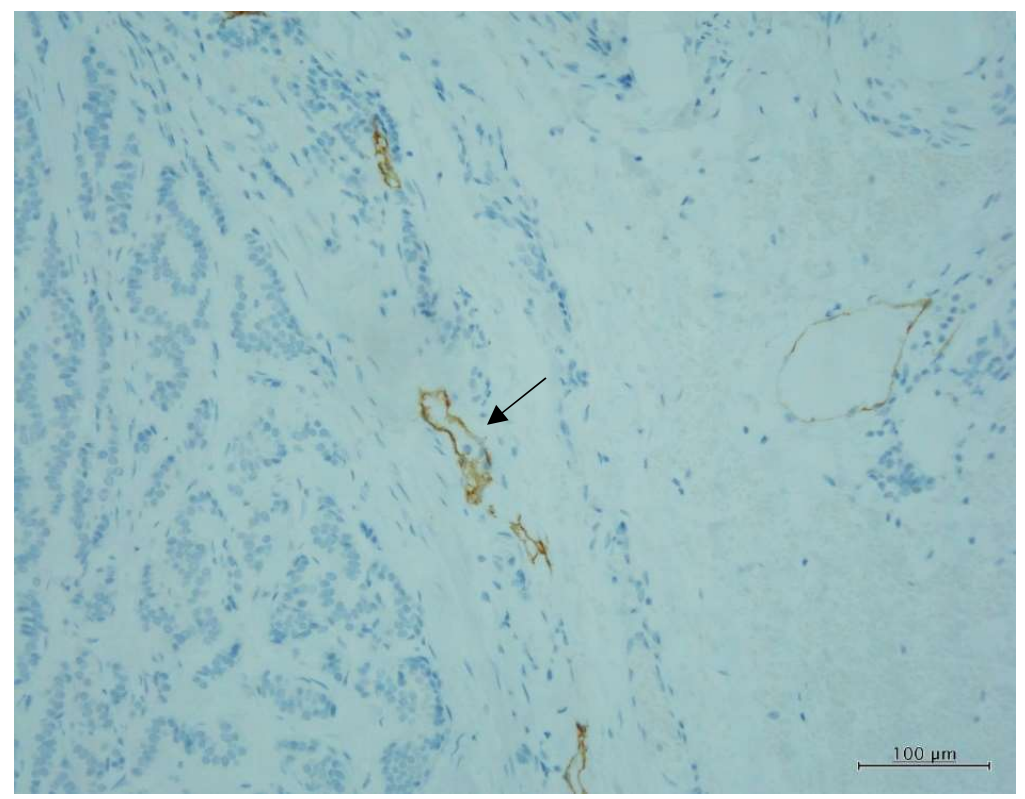

Figure 1. D2-40 immunohistochemical stain showing lymphatic invasion (arrow) in the lymphatic vessels that had been cut diagonally. $(\times 100$.)

The univariate analysis revealed significant differences in tumor size (Odds ratio [OR] $=1.033,95 \%$ confidence interval [CI]: 1.001-1.066, $\mathrm{p}=0.044)$, depth $(\mathrm{OR}=3.957,95 \% \mathrm{CI}$ : 1.306-11.992, $\mathrm{p}=0.015)$, MIB-1 index (OR $=6.800,95 \%$ CI: 1.082-42.731, $\mathrm{p}=0.041$ ), lymphatic invasion (OR $=12.677,95 \% \mathrm{CI}$ : $1.888-84.965, \mathrm{p}=0.009)$, and NET grade (OR $=1.724,95 \% \mathrm{CI}$ : 1.874-24.131, $\mathrm{p}=0.003$ ) in cases of lymph node metastases, although statistical values could not be obtained for venous invasion (Table 2). Similarly, for all other metastases, the univariate analysis identified significant differences in tumor size (OR $=1.097,95 \%$ CI: 1.020-1.180, $\mathrm{p}=0.013)$, depth (OR $=9.253,95 \%$ CI: 2.038-42.013, $\mathrm{p}=0.004)$, MIB-1 index $(\mathrm{OR}=6.111,95 \%$ CI: 1.222-30.572, $\mathrm{p}=0.028)$, lymphatic invasion $(\mathrm{OR}=6.000,95 \%$ CI: 1.172 30.725, $\mathrm{p}=0.032$ ), venous invasion ( $\mathrm{OR}=35.000,95 \% \mathrm{CI}: 3.700-331.059, \mathrm{p}=0.002)$, and NET grade (OD $=14.900,95 \%$ CI: 2.979-74.529, $\mathrm{p}=0.001$ ) (Table 3 ). However, only NET grade exhibited a significant difference in the multivariate analysis. In the multivariate analysis, we used the variable increase method, and each variable was included in the multivariate model based on the likelihood ratio. Therefore, the OR was only calculated for the NET grade. 
Table 2. Logistic regression analysis for lymph node metastases

\begin{tabular}{|c|c|c|c|c|c|c|c|c|}
\hline \multirow[b]{3}{*}{ Age (per 1 year) } & \multicolumn{5}{|c|}{ Univariate analysis } & \multicolumn{3}{|c|}{ Multivariate analysis } \\
\hline & \multirow{2}{*}{$\begin{array}{c}\text { OR } \\
1.074\end{array}$} & \multicolumn{3}{|c|}{$95 \%$ CI } & \multirow{2}{*}{$\frac{\text { p-value }}{0.092}$} & \multirow{2}{*}{$\begin{array}{c}\text { OR } \\
-\end{array}$} & \multirow[t]{2}{*}{$95 \% \mathrm{CI}$} & \multirow[t]{2}{*}{ p-value } \\
\hline & & 0.988 & , & 1.166 & & & & \\
\hline Sex, Male (vs. Female) & 0.375 & 0.066 & , & 2.120 & 0.267 & - & & \\
\hline Body mass index (per $1 \mathrm{~kg} / \mathrm{m}^{2}$ ) & 0.866 & 0.682 & , & 1.100 & 0.239 & - & & \\
\hline Size (per $1 \mathrm{~mm}$ ) & 1.033 & 1.001 & , & 1.066 & 0.044 & n.e. & & \\
\hline Location & & & & & & - & & \\
\hline Rectum & 1.000 & & ref & & & & & \\
\hline Stomach & n.c. & & & & & & & \\
\hline Duodenum & 6.000 & 0.321 & , & 112.258 & 0.231 & & & \\
\hline Esophagus & n.c. & & & & & & & \\
\hline Intestine & n.c. & & & & & & & \\
\hline Large intestine & n.c. & & & & & & & \\
\hline Pancreas & n.c. & & & & & & & \\
\hline Depth (per 1) & 3.957 & 1.306 & , & 11.992 & 0.015 & n.e. & & \\
\hline MIB-1 index, $>3 \%$ (vs. $<3 \%$ ) & 6.800 & 1.082 & , & 42.731 & 0.041 & n.e. & & \\
\hline Lymphatic invasion, Yes (vs. No) & 12.667 & 1.888 & , & 84.965 & 0.009 & n.e. & & \\
\hline Venous invasion, Yes (vs. No) & n.c. & & & & & - & & \\
\hline $\begin{array}{l}\text { Lymphatic invasion/Venous } \\
\text { invasion }\end{array}$ & & & & & & - & & \\
\hline Neither & 1.000 & & ref & & & & & \\
\hline Either one/Both & n.c. & & & & & & & \\
\hline Grade (per 1) & 6.724 & 1.874 & , & 24.131 & 0.003 & 6.724 & $1.874, \quad 24.131$ & 0.003 \\
\hline
\end{tabular}
entered.

OR, odds ratio; 95\% CI, 95\% confidence interval; ref, reference; n.c., not calculable; n.e., not

Variables that were significant in the univariate analysis were used in the multivariate analysis (variable increase method: likelihood ratio).

Values in bold indicate significant factors. 
Table 3. Logistic regression analysis for all metastases

\begin{tabular}{|c|c|c|c|c|c|c|c|c|c|}
\hline \multirow[b]{3}{*}{ Age (per 1 year) } & \multicolumn{5}{|c|}{ Univariate analysis } & \multicolumn{4}{|c|}{ Multivariate analysis } \\
\hline & \multirow{2}{*}{$\begin{array}{c}\text { OR } \\
1.066\end{array}$} & \multicolumn{3}{|c|}{$95 \% \mathrm{CI}$} & \multirow{2}{*}{$\begin{array}{c}\text { p-value } \\
0.077\end{array}$} & \multirow{2}{*}{$\begin{array}{c}\text { OR } \\
-\end{array}$} & \multicolumn{2}{|r|}{$95 \%$ CI } & \multirow[t]{2}{*}{ p-value } \\
\hline & & 0.993 & , & 1.145 & & & & & \\
\hline Sex, Male (vs. Female) & 0.355 & 0.076 & , & 1.667 & 0.189 & - & & & \\
\hline Body mass index (per $1 \mathrm{~kg} / \mathrm{m}^{2}$ ) & 0.901 & 0.737 & , & 1.102 & 0.309 & - & & & \\
\hline Size (per $1 \mathrm{~mm}$ ) & 1.097 & 1.020 & , & 1.180 & 0.013 & n.e. & & & \\
\hline Tumor location & & & & & & - & & & \\
\hline Rectum & 1.000 & & ref & & & & & & \\
\hline Stomach & n.c. & & & & & & & & \\
\hline Duodenum & 2.900 & 0.219 & , & 38.320 & 0.419 & & & & \\
\hline Esophagus & n.c. & & & & & & & & \\
\hline Intestine & n.c. & & & & & & & & \\
\hline Large intestine & n.c. & & & & & & & & \\
\hline Pancreas & 7.250 & 0.443 & , & 118.700 & 0.165 & & & & \\
\hline Depth (per 1) & 9.253 & 2.038 & , & 42.013 & 0.004 & n.e. & & & \\
\hline MIB-1 index, $>3 \%$ (vs. $<3 \%$ ) & 6.111 & 1.222 & , & 30.572 & 0.028 & n.e. & & & \\
\hline Lymphatic invasion, Yes (vs. No) & 6.000 & 1.172 & , & 30.725 & 0.032 & n.e. & & & \\
\hline Venous invasion, Yes (vs. No) & 35.000 & 3.700 & , & 331.059 & 0.002 & n.e. & & & \\
\hline $\begin{array}{l}\text { Lymphatic invasion/Venous } \\
\text { invasion }\end{array}$ & & & & & & n.e. & & & \\
\hline Neither & 1.000 & & ref & & & & & & \\
\hline Either one/both & 17.500 & 1.940 & , & 157.881 & 0.011 & & & & \\
\hline Grade (per 1) & 14.900 & 2.979 & , & 74.529 & 0.001 & 14.900 & 2.979 & , 74.529 & 0.001 \\
\hline
\end{tabular}
entered.

OR, odds ratio; $95 \% \mathrm{CI}$, 95\% confidence interval; ref, reference; n.c., not calculable; n.e., not

Variables that were significant in the univariate analysis were used in the multivariate analysis (variable increase method: likelihood ratio)

Values in bold indicate significant factors.

\subsection{Correlations with Lymph Node Metastasis and All Other Types of Metastasis}

We investigated the relationship between lymph node invasion and venous invasion in cases of lymph node metastasis (Table 4) and all other types of metastasis (Table 5). For lymph node metastases, the $\mathrm{p}$ value for lymphatic invasion was 0.011 , whereas that for venous invasion was 0.000 , indicating a stronger correlation with venous invasion. Furthermore, for all metastases, the $\mathrm{p}$ value for lymphatic invasion was 0.041 , whereas that for venous invasion was 0.000 , indicating a stronger correlation with venous invasion. 
Table 4. Comparison of cases with and without lymph node metastases.

\begin{tabular}{|c|c|c|c|c|c|}
\hline & With & $\begin{array}{l}\text { ut lymph node } \\
\text { netastases } \\
(\mathrm{n}=44)\end{array}$ & & $\begin{array}{c}\text { With lymph node } \\
\text { metastases } \\
(n=6)\end{array}$ & p-value \\
\hline Lymphatic invasion & & & & & 0.011 \\
\hline No & 38 & , 86.4 & 2 &,$\quad 33.3$ & \\
\hline Yes & 6 & , 13.6 & 4 & , 66.7 & \\
\hline Venous invasion & & & & & 0.000 \\
\hline No & 36 & , 81.8 & 0 & , 0.0 & \\
\hline Yes & 8 & , 18.2 & 6 & , 100.0 & \\
\hline Lymphatic invasion/Venous invasion & & & & & 0.000 \\
\hline Neither & 31 & , 70.5 & 0 & , 0.0 & \\
\hline Either one & 12 & , 27.3 & 2 & , $\quad 33.3$ & \\
\hline Both & 1 & 2.3 & 4 & , 66.7 & \\
\hline Lymphatic invasion/Venous invasion & & & & & 0.002 \\
\hline Neither & 31 & , 70.5 & 0 & , 0.0 & \\
\hline Either one/both & 13 &,$\quad 29.5$ & 6 & , 100.0 & \\
\hline
\end{tabular}

Data are presented as n, \%; p-value: Fisher's exact test.

Values in bold are significant.

Table 5. Comparison of cases with and without all metastases.

\begin{tabular}{|c|c|c|c|c|c|}
\hline & \multicolumn{2}{|c|}{$\begin{array}{l}\text { Without all metastases } \\
\qquad(\mathrm{n}=42)\end{array}$} & \multicolumn{2}{|c|}{$\begin{array}{l}\text { With all metastases } \\
\qquad(\mathrm{n}=8)\end{array}$} & $\frac{p \text {-value }}{0.041}$ \\
\hline No & 36 & , 85.7 & 4 &,$\quad 50.0$ & \\
\hline Yes & 6 & , 14.3 & 4 & , 50.0 & \\
\hline Venous invasion & & & & & 0.000 \\
\hline No & 35 & , 83.3 & 1 & , $\quad 12.5$ & \\
\hline Yes & 7 & , $\quad 16.7$ & 7 &,$\quad 87.5$ & \\
\hline Lymphatic invasion/Venous invasion & & & & & 0.000 \\
\hline Neither & 30 & , 71.4 & 1 & 12.5 & \\
\hline Either one & 11 & , 26.2 & 3 &,$\quad 37.5$ & \\
\hline Both & 1 &,$\quad 2.4$ & 4 & , 50.0 & \\
\hline Lymphatic invasion/Venous invasion & & & & & 0.003 \\
\hline Neither & 30 & , 71.4 & 1 & , 12.5 & \\
\hline Either one/both & 12 & , 28.6 & 7 & , 87.5 & \\
\hline
\end{tabular}

Data are presented as n, \%; p-value: Fisher's exact test.

Values in bold are significant.

\section{Discussion}

The curative treatment for GEP-NET is complete resection. However, given the heterogenous nature of the lesions, indications for resection have been examined based on the organ affected. We believe that it is necessary to examine the entire NET to define its characteristics. In this study, we investigated the factors that influence lymph node metastasis and other types of metastasis in patients with GEP-NET. Our analysis revealed that both categories of metastasis were significantly associated with tumor size, depth, MIB-1 index, lymphatic invasion, venous invasion, and NET grade. This result is consistent with currently reported organ-specific results [10].

The prognosis of lymph node metastasis is important for the treatment of NETs $[13,17]$. A localized NET is an indication for endoscopic or surgical resection, but surgical resection requires complete resection of lymph node metastases; therefore, optimal methods for lymph node dissection are being investigated $[9,11,18]$. For NETs in the 
stomach, duodenum, pancreas, appendix, and rectum that are $<1 \mathrm{~cm}$ in size and intramucosal ly0 and v0 tumors are indicated for endoscopic treatment [19-24]. There is no treatment algorithm for esophageal NETs due to the scarcity of cases [25]. Endoscopic resection is not indicated for NETs in the small intestine-even if the tumor's major axis is $1 \mathrm{~cm}$ or less - due to the high rate of lymph node metastasis [26], the large number of multiple lesions [27], and technical difficulty. The amount of tumor remaining in the small intestine after resection may be larger than the piece resected; therefore, it may be necessary to consider the depth and size of the whole tumor when analyzing the data. In pancreatic NET staging, the criteria for invasion depth differ from the diagnostic criteria in other areas of the gastrointestinal tract, making them difficult to evaluate using the same criteria. For these reasons, when considering treatment options for a GEP-NET as a whole, it is necessary to consider the organ in which the tumor is situated.

Our findings indicated that venous invasion was more strongly correlated with lymph node metastases and all other metastases than lymphatic invasion. Previous studies have demonstrated that immunostaining increases the detection rate of vascular invasion $[16,28]$. However, other studies have reported contradictory data regarding the pathological identification of vascular invasion with and without immunostaining, and this discrepancy must be fully considered when comparing the data reported. Overexpression of a large number of angiogenesis-promoting molecules has been reported in NET cells, suggesting a link to metastasis [29]. A study on early-stage colorectal cancer noted that venous invasion was more useful than lymphatic invasion as a predictor of lymph node metastasis [30]. For small rectal NETs of $1.5 \mathrm{~cm}$ or less, those with vascular infiltration have been reported to have a high potential for lymph node metastasis, as high as $48.8 \%$ [31], but the authors did not compare lymphatic infiltration and venous invasion. Most studies have examined the possibility of metastasis in cases of vascular invasion, which is a combination of lymphatic invasion and venous invasion, and few have compared lymphatic invasion with venous invasion. In venous invasion, a large number of tumor cells are identified in the lumen, and the number is greater than that observed in lymphatic vessels. In lymphatic invasion, a few tumor cells are often found in the smaller lymphatic lumen. The difficulty in identifying lymphatic invasion, especially when the lymphatic vessels are cut vertically, may be related to the low rate at which lymphatic invasion is identified. These factors may explain the higher identification rate for venous invasion than for lymphatic invasion. Improving the rate at which lymphatic invasion is identified requires careful tumor identification using D2-40 immunostaining for all diagnoses. Combined evaluation with synaptophysin and other immunostaining methods can also be effective. In this study, venous invasion was observed in all cases of lymph node metastasis, and venous invasion correlates well with lymph node metastasis at present; therefore, simultaneous evaluation of vascular invasion is considered to be a sufficient index.

A previous study reported that rates of lymphatic invasion and lymph node metastasis increase significantly in cases of multiple lesions in patients with rectal NETs [32]. Furthermore, lymph node metastasis of rectal NETs has been associated with tumor size, depth of invasion, vascular invasion, and WHO grade, which is consistent with our findings for GEP-NET [33]. In addition, lymph node metastasis has been reported to affect prognosis. In patients with gastric NETs undergoing gastrectomy and lymph node dissection, prognosis is related to type I and type III of the Rindi classification, tumor size, and grade [34]. For gastric NETs, the Rindi classification is based on the presence or absence of atrophic gastritis and gastrin secretion. A treatment algorithm has been created based on this classification [35]. Comparing findings for tumors based on this classification and those based on the entire NET may provide insight into methods for improving NET classification. Previous research has indicated that venous invasion is a poor prognostic indicator in patients with pancreatic NETs [36]. In the current study, results for GEP-NET metastasis were similar to those for individual organs. In particular, the results were quite similar to those for the rectum, although most of our data were from rectal cases. Although differences in organ specificity may influence GEP-NET research, 
we believe that these findings are important for the study of tumor specificity and are reflective of the GEP-NET group.

The present study had some limitations, including its retrospective design and the low number of cases for certain organs. Further, lymph node dissection was not performed in all cases, meaning that the rate of metastasis may not have been accurate in the lymph node metastasis group, and standardized and appropriate diagnostic imaging methods for lymph node metastasis remain unclear. Follow-up for recurrence may also have been insufficient, and the overall assessment may have included unsuitable organs. Randomized controlled studies are difficult given that the guidelines indicate appropriate treatments. Further studies are required to collect necessary and sufficient data based on very accurate common diagnostic criteria. These studies should employ appropriate follow-up periods and a thorough, unified method for investigating recurrence.

\section{Conclusions}

This study investigated factors related to the metastasis of GEP-NETs based on the 2019 WHO classification. The most important factors were found to be tumor grade and vascular invasion. Of the types of vascular invasion, venous invasion was more highly correlated with metastasis than lymphatic invasion, and the analysis indicated that pathological examination of lymphatic invasion may be problematic. At present, it may be better to evaluate vascular invasion to assess NET metastasis, as it combines lymphatic and venous invasion. A unified classification system for NETs, as well as a standardized method for evaluating them, is important for the future of NET research.

Author Contributions: Conceptualization, S.K.; investigation, methodology, writing and analysis, S.K; validation and pathological analysis, M.I. investigation and validation, ;H.A., M.O.; supervision、 T.I., F.Y. and K.E. All authors have read and agreed to the published version of the manuscript.

Funding: This research received no external funding.

Institutional Review Board Statement: The study was conducted according to the guidelines of the Declaration of Helsinki, and approved by the Institutional Review Board of Jikei University School of Medicine (protocol code 33-039 [10649], approval date 10 May 2021).

Informed Consent Statement: Patient consent was waived by Jikei University School of Medicine (IRB No. 33-039 [10649]) due to the retrospective nature of the study and the use of anonymized data.

Data Availability Statement: The data presented in this study are available in this article.

Acknowledgments: We would like to thank Dr Koji Nomura for his pathological assessment.

Conflicts of Interest: The authors declare no conflicts of interest.

\section{References}

1. $\quad$ Basuroy, R.; Srirajaskanthan, R.; Ramage, J.K. Neuroendocrine Tumors. Gastroenterol. Clin. North Am.; PMID 2016, 45 (3), $487-$ 507. 27546845 DOI: 10.1016/i.gtc.2016.04.007].

2. Gonzalez, R.S. Diagnosis and Management of Gastrointestinal Neuroendocrine Neoplasms. Surg. Pathol. Clin.; PMID 2020, 13 (3), 377-397. 32773190 DOI: 10.1016/j.path.2020.04.002].

3. Cives, M.; Strosberg, J.R. Gastroenteropancreatic Neuroendocrine Tumors. C.A. Cancer J. Clin.; PMID 2018, 68 (6), 471-487. 30295930 DOI: $10.3322 /$ caac.21493].

4. Das, S.; Dasari, A. Epidemiology, Incidence, and Prevalence of Neuroendocrine Neoplasms: Are There Global Differences? Curr. Oncol. Rep.; PMID 2021, 23 (4), 43. 33719003 DOI: 10.1007/s11912-021-01029-7].

5. Nagtegaal, I.D.; Odze, R.D.; Klimstra, D.; Paradis, V.; Rugge, M.; Schirmacher, P.; Washington, K.M.; Carneiro, F.; Cree, I.A.; WHO Classification of Tumours Editorial Board. The 2019 WHO Classification of Tumours of the Digestive System. Histopathology; PMID 2020, 76 (2), 182-188. 31433515 DOI: 10.1111/his.13975].

6. Rindi, G.; Inzani, F. Neuroendocrine Neoplasm Update: Toward Universal Nomenclature. Endocr. Relat. Cancer; PMID 2020, 27 (6), R211-R218. 32276263 DOI: 10.1530/ERC-20-0036]. 
7. Walter, M.A.; Spanjol, M.; Kollár, A.; Bütikofer, L.; Gloy, V.L.; Dumont, R.A.; Seiler, C.A.; Christ, E.R.; Radojewski, P.; Briel, M.; Kaderli, R.M. Treatment for Gastrointestinal and Pancreatic Neuroendocrine Tumours:a Network Meta-Analysis. Cochrane Database Syst. Rev. 2020 (8), Art. No.: CD013700. DOI: 10.1002/14651858.CD013700.

8. Shah, M.H.; Goldner, W.S.; Benson, A.B.; Bergsland, E.; Blaszkowsky, L.S.; Brock, P.; Chan, J.; Das, S.; Dickson, P.V.; Fanta, P.; Giordano, T.; Halfdanarson, T.R.; Halperin, D.; He, J.; Heaney, A.; Heslin, M.J.; Kandeel, F.; Kardan, A.; Khan, S.A.; Kuvshinoff, B.W.; Lieu, C.; Miller, K.; Pillarisetty, V.G.; Reidy, D.; Salgado, S.A.; Shaheen, S.; Soares, H.P.; Soulen, M.C.; Strosberg, J.R.; Sussman, C.R.; Trikalinos, N.A.; Uboha, N.A.; Vijayvergia, N.; Wong, T.; Lynn, B.; Hochstetler, C.. Neuroendocrine and Adrenal Tumors, Version 2.2021, NCCN Clinical Practice Guidelines in Oncology. J. Natl. Compr. Canc. Netw., version 2.2021. Natl. Compr. Canc. Netw. 2021; PMID 2021, 19 (7), 839-868. 34340212 DOI: 10.6004/jnccn.2021.0032].

9. Zandee, W.T.; de Herder, W.W. The Evolution of Neuroendocrine Tumor Treatment Reflected by Enets Guidelines. Neuroendocrinology; PMID 2018, 106 (4), 357-365. 29320780 DOI: 10.1159/000486096].

10. Garcia-Carbonero, R.; Sorbye, H.; Baudin, E.; Raymond, E.; Wiedenmann, B.; Niederl,e B.; Sedlackova, E.; Toumpanakis, C.; Anlauf ,M.; Cwikla, J..M.; Calin, M.; O'Toole, D.; Perren A, Vienna Consensus Conference participants. ENETS Consensus Guidelines for High-Grade Gastroenteropancreatic Neuroendocrine Tumors and Neuroendocrine Carcinomas. Neuroendocrinology. 2016, 103, 186-194. [PMID: 26731334. DOI: 10.1159/000443172].

11. Shah, M.H.; Goldner, W.S.; Halfdanarson, T.R.; Bergsland, E.; Berlin, J.D.; Halperin, D.; Chan, J.; Kulke, M.H.; Benson, A.B.; Blaszkowsky, L.S.; Eads, J.; Engstrom, P.F.; Fanta, P.; Giordano, T.; He, J.; Heslin, M.J.; Kalemkerian, G.P.; Kandeel, F.; Khan, S.A.; Kidwai, W.Z.; Kunz, P.L.; Kuvshinoff, B.W.; Lieu, C.; Pillarisetty, V.G.; Saltz, L.; Sosa, J.A.; Strosberg, J.R.; Sussman, C.A.; Trikalinos, N.A.; Uboha, N.A.; Whisenant, J.; Wong, T.; Yao, J.C.; Burns, J.L.; Ogba, N.; Zuccarino-Catania, G.. NCCN Guidelines Insights: Neuroendocrine and Adrenal Tumors, Version 2.2018. J. Natl. Compr. Canc. Netw., version 2.2018. Natl. Compr. Canc. Netw. 2018; PMID 2018, 16 (6), 693-702. 29891520. DOI: 10.6004/jnccn.2018.0056].

12. Eto, K.; Yoshida, N.; Ikegami, S.; Iwatsuki, M.; Baba, H. Surgical Treatment for Gastrointestinal Neuroendocrine Tumors. Ann. Gastroenterol. Surg. 2020; PMID, 4, 652-659. 33319155 DOI: 10.1002/ags3.12396].

13. Martin, J.A.; Warner, R.R.P.; Aronson, A.; Wisnivesky, J.P.; Kim, M.K. Lymph Node Metastasis in the Prognosis of Gastroenteropancreatic Neuroendocrine Tumors. Pancreas; PMID 2017, $46 \quad$ (9), $1214-1218 . \quad \underline{28902794}$ DOI: 10.1097/MPA.0000000000000921].

14. WHO Classification of Tumors Editorial Board, WHO Classification of Tumors. Digestive System Tumors, 5th ed.; international Agency for Research on Cancer (LARC): Lyon; France, 2019.

15. Raica, M.; Cimpean, A.M.; Ribatti, D. The Role of Podoplanin in Tumor Progression and Metastasis. Anticancer Res. 2008, 28 (5B), 2997-3006. PMID: 19031946.

16. Kitagawa, Y.; Ikebe, D.; Hara, T.; Kato, K.; Komatsu, T.; Kondo, F.; Azemoto, R.; Komoda, F.; Tanaka, T.; Saito, H.; Itami, M.; Yamaguchi, T.; Suzuki, T. Enhanced Detection of Lymphovascular Invasion in Small Rectal Neuroendocrine Tumors Using D240 and Elastica Van Gieson Immunohistochemical Analysis. Cancer Med. 2016, 5 (11), 3121-3127. [ PMID, 27748061 DOI: 10.1002/cam4.935.

17. Sohn, B.; Kwon, Y.; Ryoo, S.B.; Song, I.; Kwon, Y.H.; Lee, D.W.; Moon, S.H.; Park, J.W.; Jeong, S.Y.; Park, K.J.; Jeong, S.Y.; Park ,K Predictive Factors for Lymph Node Metastasis and Prognostic Factors for Survival in Rectal Neuroendocrine Tumors. J. Gastrointest. Surg.; PMID 2017, 21 (12), 2066-2074. 29047070 DOI: 10.1007/s11605-017-3603-y].

18. Dasari, A.; Shen, C.; Halperin, D.; Zhao, B.; Zhou, S.; Xu, Y.; Shih, T.; Yao, J.C. Trends in the Incidence, Prevalence, and Survival Outcomes in Patients with Neuroendocrine Tumors in the United States. JAMA Oncol.; PMID 2017, 3 (10), 1335-1342. 28448665 DOI: 10.1001/jamaoncol.2017.0589].

19. Zhou, X.; Xie, H.; Xie, L.; Li, J.; Fu, W. Factors Associated with Lymph Node Metastasis in Radically Resected Rectal Carcinoids: A Systematic Review and Meta-Analysis. J. Gastrointest. Surg.; PMID 2013, 17 (9), 1689-1697. 23818123 DOI: 10.1007/s11605-0132249-7].

20. Konishi, T.; Watanabe, T.; Kishimoto, J.; Kotake, K.; Muto, T.; Nagawa, H.; Japanese Society for Cancer of the Colon and Rectum. Prognosis and Risk Factors of Metastasis in Colorectal Carcinoids: Results of a Nationwide Registry Over 15 Years. Gut; PMID 2007, 56 (6), 863-868. 17213340 DOI: 10.1136/gut.2006.109157].

21. Soga, J. Carcinoids of the Rectum: An Evaluation of 1271 Reported Cases. Surg. Today; PMID 1997, 27 (2), 112-119. 9017986 DOI: $10.1007 /$ BF02385898].

22. Shields, C.J.; Tiret, E.; Winter, D.C.; International Rectal Carcinoid Study Group. Carcinoid Tumors of the Rectum: A MultiInstitutional International Collaboration. Ann. Surg.; PMID 2010, $252 \quad$ (5), $750-755 . \quad \underline{21037430}$ DOI: $10.1097 / S L A .0 b 013 \mathrm{e} 3181 \mathrm{fb} 8 \mathrm{df6}]$.

23. Sato, Y.; Hashimoto, S.; Mizuno, K.; Takeuchi, M.; Terai, S. Management of Gastric and Duodenal Neuroendocrine Tumors. World J. Gastroenterol.; PMID 2016, 22 (30), 6817-6828. 27570419 DOI: 10.3748/wjg.v22.i30.6817].

24. Falconi, M.; Eriksson, B.; Kaltsas, G.; Bartsch, D.K.; Capdevila, J.; Caplin, M.; Kos-Kudla, B.; Kwekkeboom, D.; Rindi, G.; Klöppel, G.; Reed, N.; Kianmanesh, R.; Jensen, R.T.; Vienna Consensus Conference participants. Enets Consensus Guidelines Update for the Management of Patients with Functional Pancreatic Neuroendocrine Tumors and Non-Functional Pancreatic Neuroendocrine Tumors. Neuroendocrinology; PMID 2016, 103 (2), 153-171. 26742109 DOI: 10.1159/000443171].

25. Giannetta, E.; Guarnotta, V.; Rota, F.; de Cicco, F.; Grillo, F.; Colao, A.; Faggiano, A.; Nike. A Rare Rarity: Neuroendocrine Tumor of the Esophagus. Crit. Rev. Oncol. Hematol.; PMID 2019, 137, 92-107. 31014519 DOI: 10.1016/j.critrevonc.2019.02.012]. 
26. Walsh, J.C.; Schaeffer, D.F.; Kirsch, R.; Pollett, A.; Manzoni, M.; Riddell, R.H.; Albarello, L. Ileal “Carcinoid” Tumors-Small Size Belies Deadly Intent: High Rate of Nodal Metastasis in Tumors $\leq 1$ Cm in Size. Hum. Pathol.; PMID 2016, 56, 123-127. 27327193 DOI: 10.1016/j.humpath.2016.05.023].

27. Pasquer, A.; Walter, T.; Rousset, P.; Hervieu, V.; Forestier, J.; Lombard-Bohas, C.; Poncet, G. Lymphadenectomy during Small Bowel Neuroendocrine Tumor Surgery: The Concept of Skip Metastases. Ann. Surg. Oncol.; PMID 2016, 23 (Suppl 5), 804-808. 27613554 DOI: 10.1245/s10434-016-5574-8].

28. Kang, H.S.; Kwon, M.J.; Kim, T.H.; Han, J.; Ju, Y.S. Lymphovascular Invasion as a Prognostic Value in Small Rectal Neuroendocrine Tumor Treated by Local Excision: A Systematic Review and Meta-Analysis. Pathol. Res. Pract.; PMID 2019, 215 (11), 152642. 31585816 DOI: 10.1016/j.prp.2019.152642].

29. Cives, M.; Pelle', E.; Quaresmini, D.; Rizzo, F.M.; Tucci, M.; Silvestris, F. The Tumor Microenvironment in Neuroendocrine Tumors: Biology and Therapeutic Implications. Neuroendocrinology; PMID 2019, $109 \quad$ (2), 83-99. 30699437 DOI: $10.1159 / 000497355$.

30. Gleeson, F.C.; Levy, M.J.: Dozois, E.J.; Lason, D.W.; Michel, L.; Song, W.K. Boardman, L.A. Endoscopically identified welldifferentiated rectal carcinoid tumors: impact of tumor size on the natural history and outcomes. Gastrointest Endosc.. 2014, 80,144-151. [PMID: 24462168 DOI: 10.1016/j.gie.2013.11.031] .

31. Nam, SJ.; Kim, CK.; Chang, HJ.; Jeon, HH.; Kim J.; Kim, SY. Risk Factors for Lymph Node Metastasis and Oncologic Outcomes in Small Rectal Neuroendocrine Tumors with Lymphovascular Invasion. Gut Liver. 2021, [DOI: 10.5009/gnl20364]

32. Nishikawa, Y.; Chino, A.; Ide, D.; Saito, S.; Igarashi, M.; Takamatsu, M.; Fujisaki, J.; Igarashi, Y. Clinicopathological Characteristics and Frequency of Multiple Rectal Neuroendocrine Tumors: A Single-Center Retrospective Study. Int. J. Colorectal Dis.; PMID 2019, 34 (11), 1887-1894. 31630212 DOI: 10.1007/s00384-019-03405-Z].

33. Wang, Y.; Zhang, Y.; Lin, H.; Xu, M.; Zhou, X.; Zhuang, J.; Yang, Y.; Chen, B.; Liu, X.; Guan, G. Risk factors for lymph node metastasis in rectal neuroendocrine tumors: A recursive partitioning analysis based on multicenter data. $J$ Surg Oncol. 2021,124,:1098-1105. [PMID: 34291822 DOI: 10.1002/jso.26615]

34. Hanna,A.; Kim-Kiselak, C.; Tang, R.; Metz, DC.; Yang, Z.; DeMatteo, R.; Fraker, DL.; Roses, RE.. Gastric Neuroendocrine Tumors: Reappraisal of Type in Predicting Outcome. Ann Surg Oncol. 2021, 13. [PMID: 34120268 DOI: 10.1245/s 10434-021-10293-7]

35. Sato Y, Hashimoto S, Mizuno K, Takeuchi M, Terai S. Management of gastric and duodenal neuroendocrine tumors. World J Gastroenterol 2016; 14; 22: 6817-6828 [PMID: 27570419 DOI: 10.3748/wjg.v22.i30.6817]

36. Nanno, Y.; Toyama, H.; Otani, K.; Asari, S.; Goto, T.; Terai, S.; Ajiki, T.; Zen, Y.; Fukumoto, T.; Ku, Y. Microscopic Venous Invasion in Patients with Pancreatic Neuroendocrine Tumor as a Potential Predictor of Postoperative Recurrence. Pancreatology; PMID 2016, 16 (5), 882-887. 27350059 DOI: 10.1016/j.pan.2016.06.008] $]$. 